\title{
Building Commitment to Continue Studies among Asian Students
}

\author{
Amarjit Gill $^{*}, 1$, Nahum Biger ${ }^{2}$ and Harjinder Dhaliwal ${ }^{3}$ \\ ${ }^{1}$ College of Business Administration, TUI University, CA, 90630, USA \\ ${ }^{2}$ College of Business Administration, TUI University, CA, 90630, USA \\ ${ }^{3}$ Kwantlen University College, Surrey, BC Canada
}

\begin{abstract}
This study examines the impact of Asian student dependence on faculty to learn course material and student satisfaction with faculty support on their commitment to continuing study. Asian students enrolled in business management program at colleges and universities in British Columbia, Canada were surveyed to find out if the degree of their dependence on faculty to learn course material and their satisfaction with faculty support enhance their commitment to continue to study at their institute of higher education. Results show that the degree of students' perceived commitment to continuing study is positively related to the degree of student dependence on faculty to learn course material and their satisfaction with faculty support. The paper also offers useful insights for the North American colleges and universities based on empirical evidence.
\end{abstract}

Keywords: Student dependence on faculty to learn course material, student satisfaction with faculty support, commitment to continue studies by students, Asian students, student retention.

\section{INTRODUCTION}

The issue of student retention has been found to be prevalent in North American Colleges and Universities [1]. Business motives have led Organization for Economic Cooperation and Development (OECD) countries to liberalize their policies to increase import and export in education, which in turn, increased number of international students in North American countries. The international market for education services has to a large extent been demand-driven, particularly by students from the rapidly emerging countries of North and South-East Asia [2]. Foreign students represent an important source of export revenue for many colleges and universities in the United States and Canada.

Although foreign students represent an important source of export revenue, they pose some challenges for North American colleges and universities because of their different learning styles. Students from Asian countries have different behaviors, cultures, attitudes, and learning habits which create teaching challenges for North American instructors/professors [3]. In recent years, universities and colleges noticed retention rate among Asian students [1]. For decades getting more students into colleges and universities has been the top priority of America's higher education leaders. The reality is that a few who go to college/university successfully complete their studies and obtain an academic degree. A recent study indicated for example that only 54 percent of students entering four-year colleges in 1997 had a degree six years later [4].

To cope with student retention issues, colleges and universities have started to consider students as important customers [5]. They now emphasize student satisfaction with faculty support as an important contributor to retention.

*Address correspondence to this author at the College of Business Administration, TUI University, CA 90630, USA; E-mail: AGill@tuiu.edu
Higher education institutions have been trying continually to find new and innovative approaches to retain students [6].

Since faculty members do not only teach but also act as advisors [7], it is important to understand student dependence on faculty to learn course material and student satisfaction with faculty support. These key elements should enhance students' commitment to continuing their study at their own college or university. The purpose of this study was to explore these relationships among student's dependence of instructors in their learning experience and their satisfaction with faculty support, and their propensity to continue to study at the same institution of higher learning. We focus on Asian students because of their unique type of dependence on instructors. In addition, this study seeks to extend and update previous studies that did not focus on foreign students in North American universities.

Guolla's [5] study investigated the impact of multiple teaching quality factors on course satisfaction and instructor satisfaction as perceived by students. Poirier's [8] study investigated the relationships between cognitive style of college level industrial arts and business students and their academic success as measured by college grade point average, as well as other variables such as high school rank, ACT scores, sex, and cognitive style of the teacher. Helgesen and Nesset's [9] study examined two models to explore the relationships among service quality, facilities, student satisfaction, image of the university college, and image of the study program, with student loyalty as the ultimate dependent variable. Alves and Rapaso's [10] study tested an explanatory model of student satisfaction in higher education by utilization of structural equations and showed that the consequence of satisfaction was student loyalty.

The current study adds to the previous studies by investigating relationships between of Asian student dependence on 
faculty to learn course material and student satisfaction with faculty support and their perceived commitment to continue to study.

\section{STUDENT DEPENDENCE ON FACULTY TO LEARN COURSE MATERIAL AND THEIR COMMITMENT TO CONTINUE THEIR STUDY}

Student dependence on faculty to learn course material refers to the student who sees instructors/professors as source of support and depends on them to learn course material. Student success in education does not only depend on him or her but also on instructors/professors who teach in the classroom. Most of the students depend on their instructors/professors to learn course material. Students consider instructors/professors an important source of information [5]. Instructors'/professors' teaching styles impact positively or negatively on students in their development of reading, writing, analytical, critical thinking skills. It is therefore important to apply different teaching methods such as power point presentations, office and online tutoring, class notes, etc., to enhance student learning and to make teaching interesting and effective. Such teaching methods may be considered an adequate support to enhance student learning and to help the student complete the degree program.

Poirier [8] found a significant positive relationship between student academic achievement and an instructor's teaching style. Teacher-to-student interactions affect students' learning achievement positively. Although excessive student dependency creates problems for both instructors/professors and students, it builds commitment to continue their studies among students.

Asian students in particular create challenges for North American colleges and universities because of their different attitudes and tendency to depend on instructors/professors to learn course material. If such conjectures are correct, then North American colleges and universities that cater to Asian students' dependence expectations to learn course material may improve the tendency of these students to commit to continue their study at the same college or university.

Hence, the following hypothesis was formulated:

H1: The higher the degree of perceived student dependence on faculty to learn course material by Asian students, the higher the degree of commitment to continue their studies at their college or university.

\section{RELATIONSHIP BETWEEN STUDENT SATISFAC- TION WITH FACULTY SUPPORT AND THE COM- MITMENT TO CONTINUE THE STUDY}

Just as it is important to satisfy customers to retain them in for-profit institutions, academic institutions found that satisfying admitted students contribute to student retention [11]. Factors such as: (i) faculty support to students, (ii) quality of education, (iii) faculty teaching styles, etc., have positive impact on student satisfaction $[5,12,8])$.

Satisfaction with faculty support is very important for Asian students in their tendency to continue study at the same college/university. Student satisfaction builds student loyalty to an educational institution $[9,10]$. Guolla [5] indicates that students consider themselves expert consumers of the education service experience since they have taken nu- merous courses previously. Therefore, satisfaction with faculty support is very important to build commitment to continue their studies particularly in case of Asian students at North American colleges/universities. Taking this further in the post-consumption process from an aggregate perspective, highly satisfied students with faculty support return as graduate and post graduate students.

Hence, the following hypothesis was formulated:

H2: The higher the degree of perceived satisfaction with faculty support by Asian students, the higher the degree of commitment to continuing their study with North American colleges/universities.

\section{METHOD}

\section{Research Design}

This study utilized a survey research (a non-experimental field study design). The research was designed to test two hypotheses. Gall, Borg, and Gall [13] also indicate that survey research is a useful tool for studying sensitive opinions, attitudes, preferences, and behaviors of individuals, particularly when the opinions are reflections of larger underlying attitudinal constructs.

\section{Measurement}

Following research by others, measures from three referent studies that were based on previous studies in marketing, education, and psychology were adopted. Measures pertaining to student dependence on faculty to learn course material were adopted from Ha, Karande, and Singhapakdi [14] and measures pertaining to student satisfaction with faculty support were taken from Estaville, Brown, and Caldwell [15]. Measures pertaining to commitment to continue their studies of students were adopted from Thomas [16].

To ensure effectiveness the questionnaire was pre-tested in one-on-one meetings with 30 respondents who were representative of potential respondents to the final questionnaire.

Age was measured by a single item which asked respondents (investors) to indicate their age group. In order to preserve respondents' privacy the categorized alternative responses were: (i) 18-29 Years, (ii) 30-39 Years, (iii) 40-49 Years, (iv) 50 Years and Over. The coding of this variable, age, referred to the mean age in each age category.

\section{Gender (i) Male (ii) Female.}

\section{Student Dependence on Faculty to Learn Course Mate- rial}

Dependence was operationalized as the extent to which Asian students depend on instructors/professors to learn course material for their: i) intellectual development, ii) personal growth, and iii) education success. Ha, Karande, and Singhapakdi [14] used the seven-item tolerance-of-freedom scale, which measures the importers' dependence on exporters. Based on confirmatory factor analysis (CFA) loading scores, four items were selected to measure the "student dependence on faculty to learn course material" variable. Scale items were reworded to apply to students in the education industry and the reliability of these re-worded items was retested. These items are: 
SD1) To what extent do you depend on your Instructor/Professor to learn course material?

SD2) To what extent is your Instructor/Professor important to you for your intellectual development?

SD3) To what extent is your Instructor/Professor important to you for your personal growth?

SD4) Overall, to what extent is your Instructor/Professor crucial for your education success?

Respondents were asked to indicate their agreement with each item, using a four-point Likert scale ranging from "None" to "Extreme." Higher scores reflect the higher level of student dependence on faculty to learn course material.

Ha, Karande, and Singhapakdi [14] reported a Cronbach alpha of .93 for the above four items. We calculated a Cronbach alpha of .83 on the responses of the thirty students who participated in the pre-test of the above scale items. All four items were included in the final questionnaire.

Student Satisfaction with Faculty Support was operationalized as the extent to which students are satisfied with: i) help from faculty members to understand course material, ii) teaching style of faculty members, and iii) education quality provided by faculty. Estaville, Brown, and Caldwell [15] used fifteen items to measure student satisfaction with an education department. We selected four items that were most suitable to measure "student satisfaction with faculty support" variable. Scale items were reworded to apply to students in the education industry and the reliability of these reworded items was re-tested. These items are:

SS1) To what extent are you satisfied with the help that you receive from your Instructor/Professor?

SS2) To what extent are you satisfied with teaching style of your Instructor/Professor?

SS3) Overall, to what extent are you satisfied with the quality of education provided by your Instructor/Professor?

Respondents were asked to indicate their agreement with each item, using a four-point Likert scale ranging from "None" to "Extreme." Higher scores reflect higher level of student satisfaction with faculty support.

Cronbach alpha was not reported by Estaville, Brown, and Caldwell [15] for the above 3 items. We calculated a Cronbach alpha of .90 on the responses of the thirty students who participated in the pre-test of the above scale items. All three items were included in the final questionnaire.

Students' Commitment to continue their studies was operationalized as the extent to which students are committed to a college/university to earn a higher degree in near future. Thomas [16] used four-item tolerance-of-freedom scale which measures student commitment to a college/university. Based on their CFA loading scores, all four items were selected to measure the "students' commitment to continue their studies" variable. Scale items were reworded to apply to students in the education industry and the reliability of these re-worded items was re-tested. These items are:

$\mathrm{SC1}$ ) To what extent do you tell your friends that this college/university is a great place to study?
SC2) To what extent is it important to you to graduate from this college/university?

SC3) To what extent do you plan to continue study at this college/university to earn a higher degree in the future?

Respondents were asked to indicate their agreement with each item, using a four-point Likert scale ranging from "None" to "Extreme." Higher scores indicate higher level of commitment to continue their studies of students at present college/university in near future.

Thomas [16] reported a Cronbach alpha of .71 for the above four items. We calculated a Cronbach alpha of .86 on the responses of the thirty students who participated in the pre-test of the above scale items. All three items were included in the final questionnaire.

\section{Sampling Frame, Questionnaire Distribution, and Collec- tion}

Asian students (Chinese, Indian, Taiwanese, Korean, and Japanese) who study in colleges and universities in the Lower Mainland of Canada area (Vancouver, Burnaby, New Westminster, Surrey, and Richmond) were chosen as a sampling frame.

\section{Sampling Method, Sampling Issues, and Possible Planned Solutions}

The current study applied a convenience (non-random) sampling method to select and recruit the research participants. This method was chosen because the colleges and universities were reluctant to participate in the research and did not allow us to obtain a list of student names and to distribute surveys to respondents this way. Therefore, there is the possibility of sampling bias (the threat to representational ability of a sample). To avoid sampling bias, colleagues, instructors, students, friends, and relatives who collected the information and conducted the survey were asked to choose research participants who are indeed representative of the population. They excluded all non-Asian students. It was also ensured that all the research participants who completed surveys offsite were Asian students. To achieve a convenience sample, a list of colleges and universities in the Lower Mainland area was created. In addition, to set up the data gathering, a mailing list of colleges' and universities', instructors', friends, students', and relatives' names and addresses were completed. Survey questionnaire bundles coupled with an instruction sheet were provided to participating instructors, students, friends, and relatives for distribution.

The sample included at least 800 research participants encompassing Asian students. A total of 187 surveys were completed. The following is the details on returned surveys:

i) 102 surveys were returned by Chinese students,

ii) 30 surveys were returned by Indian students,

iii) 35 surveys were returned by Taiwanese students,

iv) 13 surveys were returned by Korean students, and

v) 7 surveys were returned by Japanese students.

Out of 187 returned surveys, one survey was non-usable. Thus, the response rate was $23.37 \%$. The remaining popula- 
tion was assumed to be similar to the selected research participants.

Instructors, students, friends, and relatives distributed and collected the student surveys. Some of the student surveys were completed through telephone interview by the main author. Once the surveys were completed, they were picked up in person from instructors, students, friends, and relatives. Some of the completed surveys were received by mail.

\section{STUDY PROCEDURES}

Asian students in the Lower Mainland, Canada (Vancouver, Burnaby, New Westminster, Surrey, and Richmond) were studied. Instructors, students, friends, and relatives were called and visited in order to have their consent to support my research. Letters explaining the purpose of the study and asking for support were also written. Once instructors, students, friends, and relatives agreed, the questionnaire was delivered. Each packet contained the students' questionnaires together with one page of instructions and postage pre-paid return envelopes

\section{Issues Related to Confidentiality of the Research Partici- pants}

To handle confidentiality issues, all the subjects were assured that their names will not be disclosed and confidentiality will be assured. In addition, all the Asian students were requested to not disclose their name on the questionnaire. Since the research was based on the survey questionnaire, Asian students were not strictly required to respond to any specific question.

There was no obligation for the subjects to answer questions over the telephone and in person. Prior to any telephone interview, the subjects were asked for their willingness to participate. They could refuse to participate in the telephone interview. None was forced or coerced to participate.

Student Consent Letter specifically indicated that by completing the survey, subjects have consented to participate in the study. Any information that is obtained in connection with this study and that can be identified with subjects will remain confidential and will be disclosed only with subjects' written permission or as required by law.

\section{ANALYSIS AND RESULTS}

Linear regression (a statistical method that analyzes the relationship between two variables) was utilized to test hypotheses and to analyze results. Where qualitative variables were introduced into the model, their " $k$ " category levels were transformed to " $\mathrm{k}-1$ " dummy variables.

\section{Data Analysis Methods}

Measures of central tendency, variance, skewness, and kurtosis were calculated on responses to all of the items. Skewness measures for all of the items were within the range of -1.0 to +1.0 , which is considered to be an excellent range for most research that requires using statistics appropriate to normal distributions [17]. Therefore, we used statistics that assume scalar values and symmetric distributions to test our hypotheses.
Using a principle component rotation and a varimax rotation, we ran a Confirmatory Factor Analysis (CFA) on the ten items. Three factors explained $83.51 \%$ of the variance in the ten items, and all of the items loaded on the expected factors.

We factor analyzed the four "student dependence on faculty to learn course material" items and used the resultant weighted score as our "student dependence on faculty to learn course material" scale. The items loaded roughly equally on the scale. This factor explained $81.97 \%$ of the variance in the 4 items. Cronbach alpha calculated was 0.9262 on the 4 items.

We factor analyzed the three "student satisfaction with faculty support" items and used the resultant weighted score as our "student satisfaction with faculty support" scale. The items loaded roughly equally on the scale. This factor explained $88.05 \%$ of the variance in the three items. Cronbach alpha calculated was 0.9321 on the three items.

We factor analyzed the three "students' commitment to continue their studies" items and used the resultant weighted score as our "students' commitment to continue their studies" scale. The items loaded roughly equally on the scale. This factor explained $80.20 \%$ of the variance in the three items. Cronbach alpha calculated was 0.8755 on the three items.

\section{Testing of Hypotheses}

Data were processed with the Statistical Package for the Social Sciences (SPSS) computer program for Windows (version 11.5). Linear regression technique was used in order to examine acceptance or rejection of the null hypotheses. We used $\mathrm{p}<.05$ as the level of significance.

\section{Relationship Between Student Dependence on Faculty to Learn Course Material and Commitment to Continue Their Studies}

It was hypothesized that the higher the degree of perceived student dependence on faculty to learn course material by Asian students, the higher the degree of commitment to continue their studies at their college or university.

A positive relationship between perceived student dependence on faculty to learn course material and commitment to continue their studies was found (see Table 1); that is, the improvement in the degree of Asian students' commitment to continue their studies is related to the improvement in the degree of perceived their dependence on faculty to learn course material. Thus, the improvement in the degree of commitment to continue their studies is a function of the degree of Asian students' perceived dependence on faculty to learn course material

\section{Relationship Between Student Satisfaction with Faculty Support and Commitment to Continuing Studies}

It was hypothesized that the higher the degree of perceived satisfaction with faculty support by Asian students, the higher the degree commitment to continuing their study with North American colleges/universities.

A positive relationship between perceived student satisfaction with faculty support and commitment to continue their studies was found (see Table 1); that is, the improve- 
Table 1. Asian Students' Commitment to Continue Their Studies as Functions of Student Dependence on Faculty to Learn Course Material and Student Satisfaction with Faculty Support ${ }^{\mathrm{a}, \mathrm{b}}$

\begin{tabular}{|c|c|c|c|c|c|}
\hline & Un-Standardized Coefficients & Std. Error & Standardized Coefficients & t & Sig. \\
\hline \hline (Constant) & 0.716 & 0.350 & & 2.046 & 0.042 \\
\hline Student Dependence & 0.398 & 0.067 & 0.398 & 5.974 & 0.000 \\
\hline Student Satisfaction & 0.374 & 0.067 & 0.374 & 5.597 & 0.000 \\
\hline Age & -0.030 & 0.014 & -0.116 & -2.181 & 0.031 \\
\hline Gender & 0.108 & 0.107 & 0.054 & 1.006 & 0.316 \\
\hline
\end{tabular}

${ }^{a}$ Dependent Variable: Commitment to continue their studies.

${ }^{b}$ Independent Variables: Student Dependence on Faculty to Learn Course Material, Student Satisfaction with Faculty Support, Age, and Gender. Gender was dealt with as a single dummy variable with male $v s$ female the zero-one variable. Note that the gender dummy variable is not at all significant.

${ }^{c}$ Multiple Linear Regression.

ment in the degree of perceived Asian students' commitment to continue their studies is related to the improvement in the degree of perceived student satisfaction with faculty support.

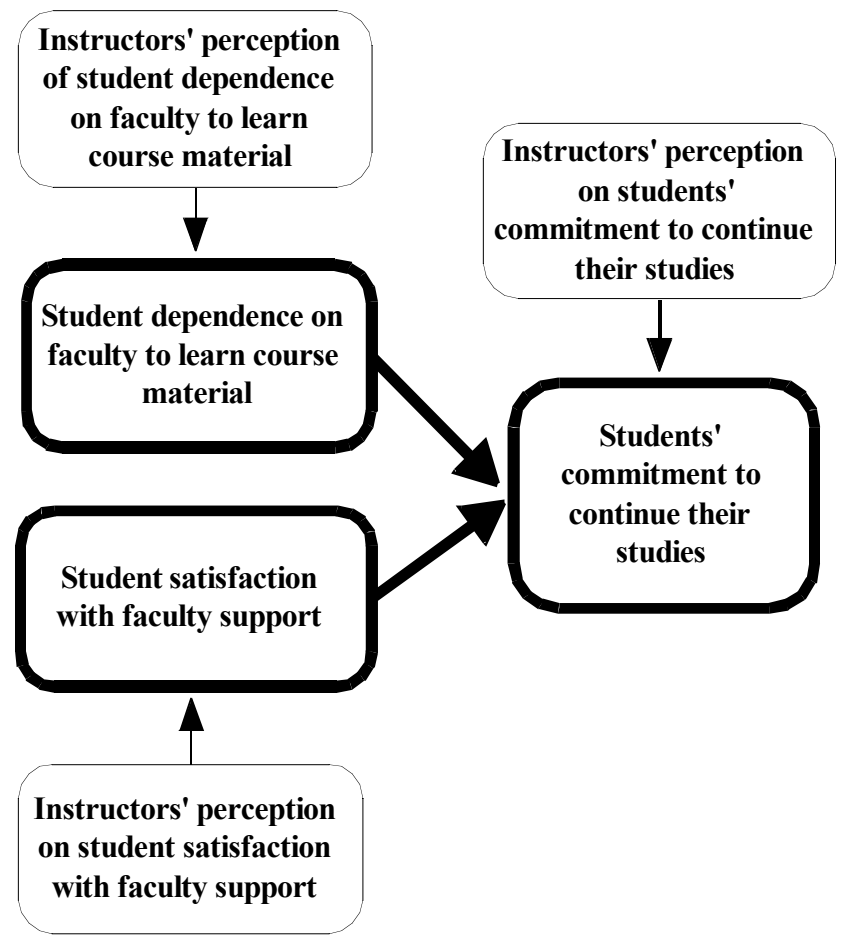

Fig. (1). Student dependence on faculty to learn course material, student satisfaction with faculty support and Commitment to continue their studies ${ }^{\mathrm{a}, \mathrm{b}}$.

${ }^{a}$ Original hypotheses are shown as boxes with thicker lines connected by thicker lines.

${ }^{b}$ Conjectures are shown as boxes with thinner lines connected by thinner lines.

It was found that around $50 \%\left(\mathrm{R}^{2}=0.502\right)$ of the variance in the degree of perceived commitment to continue their studies by Asian students can be explained by the degree of perceived dependence on faculty to learn course material, satisfaction with faculty support, and by their age. We also found a significant relationship between Asian students' age and commitment to continue their studies. Conversely no significant relationship between gender and commitment to continue their studies [see Table 1] was found.

\section{DISCUSSION}

The main purpose of this study was to determine whether the degree of perceived commitment to continue the studies by Asian students is related to the degree of student dependence on faculty to learn course material and student satisfaction with faculty support. This was done by surveying a sample of Asian students who were visiting to study in British Columbia, Canada. These students' perceptions and judgments are the basis of the findings that the degree of perceived commitment to continue the studies is related to the degree of student dependence on faculty to learn course material and student satisfaction with faculty support at the North American colleges/universities. This lends some support to Guolla's [5], Poirier's [8], Helgesen and Nesset's [9], and Alves and Rapaso's [10] findings.

Students play a boundary-spanning role where they interact with many individuals from inside (fellow students, administrative staff, and instructors/professors) and outside (employers) their college/university. This large role set requires students to satisfy frequently variegated needs and expectations of multiple parties, and only one of those parties is their instructor/professor. If students are not satisfied with faculty support, they tend to quit the study program. Given the costs associated with student replacement, building Asian students' commitment to continue their studies means a reduction in those costs. Therefore, it is important for North American colleges/universities to increase faculty support in order to build Asian students' commitment to continue their studies in these institutions of higher learning. Faculty support can be enhanced by offering office and online tutoring, class notes, etc.

\section{Recommendations for Future Research}

Although this study clearly shows that Asian students' commitment to continue their study is related to the degree of their dependence on faculty to learn course material and their degree of satisfaction with faculty support, additional research issues and questions must be addressed.

The relationships and variables that were examined in this study are depicted in Fig. (1) by thick lines and arrows. Also depicted by thin lines are additional variables that should be researched. They relate to instructors/professors perceptions and include:

- The degree to which instructors/professors perceive the relationship between student dependence on fac- 
ulty to learn course material and their commitment to continuing their studies, and

- The degree to which instructors/professors perceive the relationship between student satisfaction with faculty support and their commitment to continuing their studies.

\section{REFERENCES}

[1] Scoggin D, Styron R. Factors associated with student withdrawals from community college. The Community College Enterprise, 2006; 12: 111-25.

[2] Larsen K, Vincent-Lancrin S. The learning business: Can trade in international education work. Organization for Economic Cooperation and Development 2006; 235: 26-29.

[3] Salvarajah C. Cross-cultural study of Asian and European student perception; The need to understand the changing educational environment in New Zealand. Cross Cultural Management, 2006; 13: $142-150$.

[4] AP Associated Press. U.S. college drop-out rate sparks concern [Online]. 2006 Nov 20 [cited 2005]. Available from: http://www.msnbc.msn.com/id/10053859/.

[5] Guolla M. Assessing the teaching quality to student satisfaction relationship: Applied customer satisfaction research in the classroom. J Mark Theory Practice 1999; 7: 87-98.

[6] Anonymous. Academic retention indicators. Diverse Issues in Higher Education, 2005; 22: 26-26.
[7] Nadler S, Simerly RL. The effect of listening on the formation of students trust and commitment in academic advising: A study at a United States university. Int J Management, 2006; 23: 215-222.

[8] Poirier D. The field-dependence/field-independence dimensions of cognitive style as a correlate of success in post-secondary business and industrial arts programs. EdD [dissertation]. AAT: University of Missouri - Columbia; 1980

[9] Helgesen Q, Nesset E. Images, Satisfaction and Antecedents: Drivers of Student Loyalty? A Case Study of a Norwegian University College. Corporate Reputation Review, 2007; 10: 38-60.

[10] Alves H, Rapaso M. Conceptual Model of Student Satisfaction in Higher Education. Total Quality Management \& Business Excellence, 2007; 18: 571-80.

[11] DeShields Jr. OW, Kara A, Kaynak E. Determinants of business student satisfaction and retention in higher education: applying Herzberg's two-factor theory. Int J Educ Manag 2005; 19: 128-40.

[12] Umbach PD, Porter SR. How do academic departments impact student satisfaction? Understanding the contextual effects of departments. Rese Higher Educ 2002; 43: 209-34.

[13] Gall M, Borg W, Gall J. Educational research: An introduction (6th ed). White Plains, NY: Longman Publishing 1996.

[14] Ha J, Karande K, Singhapakdi A. Importers' relationships with exporters: Does culture matter? International Marketing review, 2004; $21: 447-456$.

[15] Estaville LE, Brown BJ, Caldwell S. Geography undergraduate program essentials: Retention. J Geo 2006; 105: 47-53.

[16] Thomas S. Ties that bind. J Higher Edu 2000; 71: 591-616.

[17] George D, Mallery P. SPSS for Windows. Boston: Allyn and Bacon 2001 .

(C) Gill et al.; Licensee Bentham Open.

This is an open access article distributed under the terms of the Creative Commons Attribution License (http://creativecommons.org/licenses/by/2.5/), which permits unrestrictive use, distribution, and reproduction in any medium, provided the original work is properly cited. 